\title{
Long-Term Survival Outcomes after Coronary Artery Revascularization Surgery of Bangladeshi Population: A Single Centre Study
}

Rezaul Karim, ${ }^{1}$ Masoom Siraj, ${ }^{2}$ Md. Nurul Amin, ${ }^{3}$ Mohammad Abdur Rashid, ${ }^{4}$ Hemanta I. Gomes, ${ }^{5}$

Naziat Shahrin Amin, ${ }^{6}$ F. Aaysha Cader, ${ }^{7}$ Jamal Uddin $^{8}$

\begin{abstract}
Background \& objective : Coronary artery bypass graft (CABG) surgery has given symptomatic and structural release of coronary atherosclerotic heart disease. CABG has been performed frequently for more than 30 years in Bangladesh. But there are no nationwide studies on the rate of survival in Bangladesh. The present study was undertaken to find the post CABG surgery survival outcomes and association between risk factors and survival over long time span.

Methods: We studied 650 consecutive patients' post-operative clinical data retrospectively and survival outcome data were collected prospectively who had CABG surgery from 2010 to 2015 in Ibrahim Cardiac Hospital \& Research Institute. Of the 650 patients, $84(12.9 \%)$ died after a median follow up of 4.9 years. Demographic, clinical, operative and postoperative characteristics were then compared between survived and died patients to find the factors associated with survival.

Result: Analysis revealed that younger patients were more likely to survive $[R R=1.1(95 \% C I=1.0-1.2)]$ longer than those who have had their CABG at or $>55$ years $(p=0.001)$. Males generally had a higher likelihood of survival $[R R=$ $1.1(R R=1.1(95 \% C I=0.9-1.2)]$ than their female counterparts $(p=0.038)$. Non-diabetics tend to have a better survival $[R R=2.3(95 \% C I=1.3-3.9)]$ than diabetics $(p=0.001)$. Non-smokers also have a higher chance of longer survival $[R R$ $=1.5(95 \% \mathrm{CI}=0.9-2.2)]$ than the smokers. CABG patients without CKD enjoyed longer survival $[\mathrm{RR}=1.4(95 \% \mathrm{CI}=$ $0.9-2.2)$ ] than CABG patients with CKD $(p=0.006)$. None of the operative and postoperative factors but hospital stay was associated with longer survival. The survived patients had a shorter mean hospital stay than the patients who died ( $p=$ $0.001)$. Analyses of the causes of death revealed heart disease to be the predominant cause $(38 \%)$ followed by stroke $(12 \%)$, CKD $(8 \%)$ and other causes like cancer, liver disease etc. (42\%).

Conclusion: Younger, male, non-smoker, non-diabetic patients may enjoy long-term survival following CABG surgery. Prediction of long-term survival can be used to determine the most appropriate post-discharge care strategies. This would undoubtedly help both patients and doctors to implement behavioral and therapeutic modifications to optimize benefit from surgery.

Key words: Coronary Artery Bypass Grafting (CABG), postoperative survival, factors influencing survival etc.
\end{abstract}

Authors' information:

Dr. Rezaul Karim, Associate Professor and Consultant, Department of Cardiology, Ibrahim Cardiac Hospital \& Research Institute, Shahbag, Dhaka,

${ }^{2}$ Prof. Masoom Siraj, Senior Consultant, Department of Cardiac Surgery, Ibrahim Cardiac Hospital \& Research Institute, Shahbag, Dhaka,

${ }^{3}$ Dr. Md. Nurul Amin, Assistant Professor, Department of Community Medicine, Rajshahi Medical College, Rajshahi \& Executive Editor, Ibrahim Cardiac Medical Journal, Ibrahim Cardiac Hospital \& Research Institute, Shahbag, Dhaka.

${ }^{4}$ Prof. Mohammad Abdur Rashid, Senior Consultant, Department of Cardiology, Ibrahim Cardiac Hospital \& Research Institute, Shahbag, Dhaka, Bangladesh.

${ }^{5}$ Dr. Hemanta I. Gomes, Assistant Professor and Associate Consultant, Department of Cardiology, Ibrahim Cardiac Hospital \& Research Institute, Shahbag, Dhaka,

${ }^{6}$ Naziat Shahrin Amin, Chest Physiotherapist, Physiotherapy Unit, Department of Cardiac Surgery, Ibrahim Cardiac Hospital \& Research Institute, Shahbag, Dhaka, Bangladesh.

${ }^{7}$ F. Aaysha Cader, MD (Cardiology), MRCP (UK), Registrar \& Specialist in Cardiology, Ibrahim Cardiac Hospital \& Research Institute Dhaka.

${ }^{8}$ Md. Jamal Uddin, Senior Chest Physiotherapist, Physiotherapy Unit, Department of Cardiac Surgery, Ibrahim Cardiac Hospital \& Research Institute, Shahbag, Dhaka, Bangladesh.

Corresponding author: Md. Jamal Uddin, Tel: +88-9671141-43, Fax: +88-2-9674030, E-mail address: uddinj83@gmail.com 


\section{INTRODUCTION:}

Coronary artery disease (CAD) is presently the leading cause of death worldwide. ${ }^{1}$ There has been huge improvement in the management strategies of heart disease in Bangladesh both in terms of pharmacological therapy and revascularization by either percutaneous coronary intervention or Coronary Artery Bypass Graft (CABG) surgery. But Bangladesh is still lagging behind in terms of secondary prevention by cardiac rehabilitation. ${ }^{2}$ CABG surgery was introduced nearly five decades ago and it has become clear that this operation relieves angina pectoris and improves quality of life and prolongs survival after CABG surgery. ${ }^{3-6}$ The prediction of 30-day or in-hospital mortality is popularly used to evaluate operative risk in cardiac surgery. ${ }^{7-10}$ However; this short-term mortality does not provide adequate information to guide long-term post-surgery patient management. ${ }^{11}$ 30-day mortality rates have declined over the last few decades due to advancements in surgical technologies and peri- and post-operative care. Improvement of long-term survival following cardiac surgery has now become a more concern to incorporate the management strategies for patients following CABG surgery. ${ }^{12,13}$ Prediction of long-term survival can be used to determine the most appropriate post-discharge care strategies. This would, beyond doubt, help both patient and their doctor community to implement behavioral and therapeutic modifications to optimize benefit from surgery. ${ }^{12}$

In 2017, the total number of cardiac operations done in Bangladesh by 25 hospitals was 11,674 as reported by Bangladesh Society of Cardiothoracic Anesthesiologist. ${ }^{14,15}$ Among them Ibrahim Cardiac Hospital \& Research Institute (ICHRI) is a center of excellence in cardiac care in Bangladesh, where 828 cardiac operations were done during the period. ${ }^{16}$ In-hospital morbidity and mortality of patients undergoing cardiac surgery have gradually fallen. ${ }^{17}$ Short and mid-term survival and quality of life of patients after discharge from the hospital have also improved. ${ }^{18-22}$ But longterm outcome data following CABG surgery is grossly lacking. Although mortality represents a hard end-point after surgery that is useful to benchmark the quality of operative surgery the patients desire a good long-term quality of life from their operation rather than simply a shortterm survival. In addition, as patients are increasingly offered the choice of CABG, it is of utmost importance that the surgical community will offer their patients accurate data on both long-term survival and also the likely long-term quality of life from the surgery. ${ }^{23}$

The effective improvement in functional capacity following CABG leads to a better quality of life (QoL). Return to work (RW) is recently described as a main indicator of restored life functioning and state of well-being in patients who undergo $C A B G, 24,25$ though, the return to work rate after CABG is influenced by a wide variety of cultural, social \& economic conditions. ${ }^{26,27}$ The postoperative re-admission rate is also one potential indicator of the long-term outcome of CABG. Most of the studies focused on the rate of early re-admission as a measure of the quality of medical care at the primary (index) hospitalization for CABG. ${ }^{28-31}$ As yet there have been no reports on readmission rates in a long-term perspective. Long-term morbidity, hospital readmission, return to work and activities of daily livings (ADLs) after CABG have not been studied as there are difficulties in obtaining reliable data. Survival benefits have been demonstrated after CABG in certain groups of patients. ${ }^{32}$ However, there are limited data available globally and in Bangladesh there is no data at all to help clinicians identify which patients are likely to have an improvement in their overall long-term outcomes following coronary revascularization surgery. So, the present study was intended to provide comprehensive data on the long-term survival rate, hospital readmission, return to work and state of well-being by ADLs in Bangladesh as well as to explore the association between risk factors and postoperative survival outcomes. 


\section{METHODS:}

Using Cardiac Surgery Department Register Book isolated post $C A B G$ patients were identified, who were discharged between January 1, 2010 and December 31, 2015 from Ibrahim Cardiac Hospital \& Research Institute (CHRI). However, patients who underwent emergency CABG surgery, CABG with valve or any great artery surgery with implanted ventricular assisted device were excluded. Data were collected on baseline demographics (age at operation, sex), anthropometric variables (weight and height) and preoperative risk factors (hypertension, hypercholesterolemia, diabetes, CKD, COPD, stroke, smoking status and renal dysfunction etc.), peroperative data (On or Off-pump CABG, number of grafts needed and cross-clamp time etc.) and also on post-operative clinical and surgical procedure including ICU and hospital stay. From patients their relatives' mobile numbers were collected and were contacted. A total of 1055 mobile calls were made; of them 650 responded and agreed to participate in the study by answering our structured questions. Then data on survival outcome were collected prospectively by telephone call. The primary outcome variable was post-CABG survival and secondary outcomes were hospital readmission, return to work and state of well-being assessed by ADLs.

Data were analyzed using the statistical analysis software SPSS, version 19.0 (IBM Corp, Armonk, NY). The test statistics used to analyze the data were descriptive statistics, Chi-square $\left(\chi^{2}\right)$ Test and Unpaired t-Test. While categorical data were compared between groups using Chi-square $\left(\chi^{2}\right)$ Test, continuous data were compared between groups using Student's t-Test. The level of significance was set at $5 \%$ and $p$-value $<0.05$ was considered statistically significant.

\section{RESULTS:}

Baseline characteristics of the 650 patients are illustrated in Table-I. The mean age of the study patients was $56 \pm 8$ years. A male preponderance
(88\%) was observed in the series with male to female ratio roughly being 9:1. The mean Body Mass Index (BMI) was $25 \pm 3.07 \mathrm{~kg} / \mathrm{m}^{2}$. The study subjects were generally hypertensive (79\%), followed by diabetic $(67 \%)$, dyslipidemic and smoker (39\%). Over $40 \%$ had family history ischemic heart disease (Table I). Majority (95\%) of the cases was operated on On-pump. The number of grafts needed was on an average $3 \pm 1$. The average cross-clamp time was $47 \pm 20$ minutes, while the average ICU stay and hospital stay were $3 \pm 1.6$ and $9 \pm 1.8$ days respectively (Table II). Nearly $90 \%$ of the patients attended postoperative physiotherapy training class following operation, $5 \%$ did not receive the training and $6 \%$ could hardly remember whether they received it (Table III). Evaluation of patients after a median follow up period of 4.9 years from the day of discharge demonstrates that majority $(87.1 \%)$ remain survived. Over $60 \%$ of the patients returned to work and $15 \%$ required re-hospitalization. Overall $98 \%$ were involved in activities of daily living (Table IV).

\section{Factors associated with survival:}

Younger patients (patients who underwent CABG before 55 years) were more likely to survive $[R R$ $=1.1(95 \% C I=1.0-1.2)$ ] longer than those who have had their CABG at or $>55$ years $(p=0.001)$. Males generally had a higher likelihood of survival $[R R=1.1(R R=1.1(95 \% C I=0.9-1.2)]$ than their female counterparts $(p=0.038)$. Non-diabetics tend to have a better survival $[R R=2.3(95 \% \mathrm{CI}$ $=1.3-3.9)]$ than diabetics $(p=0.001)$. Non-smokers also have a higher chance of longer survival $[R R=$ $1.5(95 \% \mathrm{CI}=0.9-2.2)]$ than the smokers. CABG patients without CKD enjoyed longer survival $[R R$ $=1.4(95 \% \mathrm{CI}=0.9-2.2)$ ] than CABG patients with CKD $(p=0.006)$ (Table $V)$. None of the operative and postoperative factors but hospital stay was associated with longer survival. The survived patients had a shorter mean hospital stay than the patients who died ( $p=0.001$ ) (Table VI). Mortality data analyses revealed that mortality rates were $2.1 \%$ at 1 year, $3.27 \%$ at 2 years, 
$8.04 \%$ at 3 years, $14.14 \%$ at 4 years, $16.84 \%$ at 5 years and $19.71 \%$ at 6 years (Fig-1). Analyses of the causes of death revealed heart disease to be the predominant cause $(38 \%)$ followed by stroke $(12 \%)$, CKD $(8 \%)$ and other causes like cancer, liver disease etc. (42\%) (Fig- 2).

\begin{tabular}{|c|c|c|}
\hline $\begin{array}{l}\text { Baseline } \\
\text { characteristics }\end{array}$ & Frequency (\%) & Mean \pm SD \\
\hline Age (years) & -- & $56 \pm 8$ \\
\hline \multicolumn{3}{|l|}{ Sex } \\
\hline Male & $571(88.0)$ & -- \\
\hline Female & $79(12.0)$ & -- \\
\hline \multicolumn{3}{|l|}{ Occupation } \\
\hline Previously involved with work & $468(72.0)$ & -- \\
\hline Retired & $163(25.0)$ & -- \\
\hline BMI & -- & $25 \pm 3.07$ \\
\hline \multicolumn{3}{|l|}{ Risk factors: } \\
\hline DM & $434(67.0)$ & -- \\
\hline HTN & $516(79.0)$ & -- \\
\hline $\mathrm{DL}$ & $388(60.0)$ & -- \\
\hline CKD & $15(2.3 .0)$ & -- \\
\hline COPD & $4(1.0)$ & -- \\
\hline \multicolumn{3}{|l|}{ Smoking status: } \\
\hline Ex-smoker & $254(39.0)$ & -- \\
\hline Non-smoker & $396(61.0)$ & -- \\
\hline Family history CAD & $275(42.0)$ & -- \\
\hline
\end{tabular}

Table II. Per- and post-operative (in-hospital) status ( $n=650$ )

$\begin{aligned} & \text { Per- and post-operative } \\ & \text { (in-hospital) status }\end{aligned} \quad$ Frequency (\%) $\quad$ Mean \pm SD

Operative procedure

$\begin{array}{cc}\text { On-pump } & 617(95.0) \\ \text { Off-pump } & 33(5.0)\end{array}$

Number of grafts needed

Cross-clamp time $(\mathrm{min})$

ICU stay (days)

Total Hospital Stay (days)
Table III. Distribution of patients by long-term outcome ( $n=650)$

$\begin{array}{lc}\text { Physiotherapy training } & \text { Frequency (\%) } \\ \text { Received } & 578(88.9) \\ \text { Not received } & 35(5.4) \\ \text { Don't know } & 37(5.7)\end{array}$

Table IV. Distribution of patients by long-term outcome* $(n=650)$

$\begin{array}{lc}\text { Follow-up long term outcome } & \text { Frequency (\%) } \\ \text { Survival rate } & 566(87.1) \\ \text { Return to work } & 397(61.0) \\ \text { Re-hospitalization rate } & 95(15.0) \\ \text { ADLs } & 637(98.0) \\ \text { * Multiple response } & \end{array}$

Table V. Association between characteristics of the patients \& survival

\begin{tabular}{|c|c|c|c|c|}
\hline \multirow[b]{2}{*}{ Risk factors* } & \multicolumn{2}{|c|}{ Outcome } & \multirow[b]{2}{*}{$p$-value } & \multirow[b]{2}{*}{$\begin{array}{l}\text { Relative Risk } \\
\text { (95\% Cl of RR) }\end{array}$} \\
\hline & $\begin{array}{l}\text { Survived } \\
(n=566)\end{array}$ & $\begin{array}{c}\text { Died } \\
(n=84)\end{array}$ & & \\
\hline
\end{tabular}

Age (years)

$\begin{array}{lllll}<55 & 247(92.5) & 20(7.5) & 0.001 & 1.1(1.0-1.2) \\ \geq 55 & 319(83.3) & 64(16.7) & & \end{array}$

Sex

$\begin{array}{lllll}\text { Male } & 503(88.1) & 68(11.9) & 0.038 & 1.1(0.9-1.2)\end{array}$

Female $\quad$ 63(79.7) 16(20.3)

Diabetes

$\begin{array}{lllll}\text { Yes } & 365(84.1) & 69(15.9) & 0.001 & 2.3(1.3-3.9)\end{array}$

No 201(93.1) 15(6.9)

Hypertension

$\begin{array}{llll}\text { Yes } & \text { 446(86.4) } & \text { 70(13.6) } & 0.338 \text { Not computed }\end{array}$

No $\quad 120(89.6) \quad 14(10.4)$

Smoking

$\begin{array}{lllll}\text { Yes } & 213(83.9) & 41(16.9) & 0.050 & 1.5(0.9-2.2) \\ \text { No } & 353(89.1) & 43(10.9) & & \end{array}$

No $\quad 353(89.1) \quad 43(10.9)$

DL

\begin{tabular}{|c|c|c|c|c|}
\hline Present & $339(87.4)$ & 49(12.6) & 0.786 & Not computed \\
\hline Absent & $227(86.6)$ & $35(13.4)$ & & \\
\hline \multicolumn{5}{|l|}{ CKD } \\
\hline Present & $9(60.0)$ & $6(40.0)$ & 0.006 & $1.4(0.9-2.2)$ \\
\hline Absent & $557(87.7)$ & $78(12.3)$ & & \\
\hline \multicolumn{5}{|c|}{ Family history of IHD } \\
\hline Present & $243(88.4)$ & $32(11.6)$ & 0.402 & Not computed \\
\hline Absent & $323(86.1)$ & $52(13.9)$ & & \\
\hline
\end{tabular}

Figures in the parentheses indicate corresponding \%; *Chi-squared $\left(\chi^{2}\right)$ Test was done to analyze the data. 


\begin{tabular}{|c|c|c|c|}
\hline \multirow{2}{*}{$\begin{array}{l}\text { Operative \& } \\
\text { postoperative factors* }\end{array}$} & \multicolumn{2}{|c|}{ Outcome } & \multirow[b]{2}{*}{ p-value } \\
\hline & $\begin{array}{l}\text { Survived } \\
(n=566)\end{array}$ & $\begin{array}{c}\text { Died } \\
(n=84)\end{array}$ & \\
\hline \multicolumn{4}{|l|}{ Pumping status } \\
\hline On-pump & $539(87.4)$ & $78(12.6)$ & 0.355 \\
\hline Off-pump & $27(81.8)$ & $6(18.2)$ & \\
\hline \multicolumn{4}{|l|}{ Number of grafts } \\
\hline$<4$ & $319(85.9)$ & $64(14.1)$ & 0.185 \\
\hline$\geq 4$ & 175(89.7) & $20(10.3)$ & \\
\hline Cross-clamp time (minutes) & $47.1 \pm 20.4$ & $49.5 \pm 22.9$ & 0.312 \\
\hline ICU stay (days) & $2.9 \pm 1.4$ & $3.1 \pm 2.2$ & 0.533 \\
\hline Total hospital stay (days) & $8.5 \pm 1.8$ & $9.4 \pm 2.2$ & 0.001 \\
\hline
\end{tabular}

Figures in the parentheses indicate corresponding \%; ${ }^{*}$ Chi-squared Test $\left(\chi^{2}\right)$ was done to analyze the data.

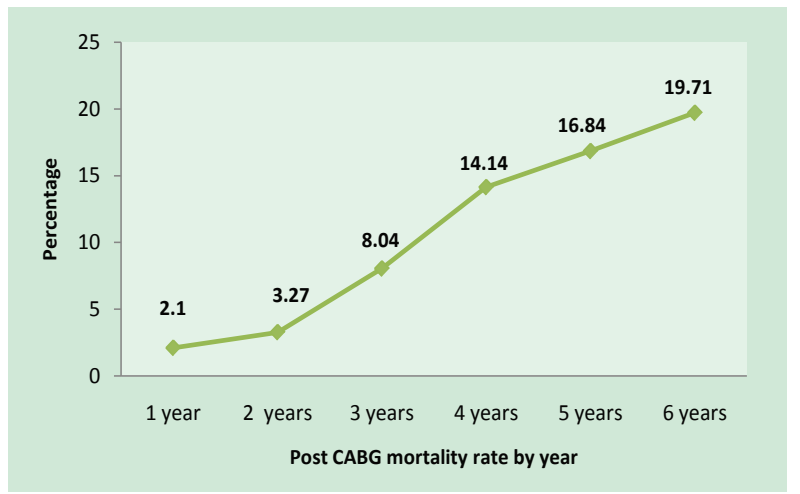

Figure-1: Post CABG mortality rate by year

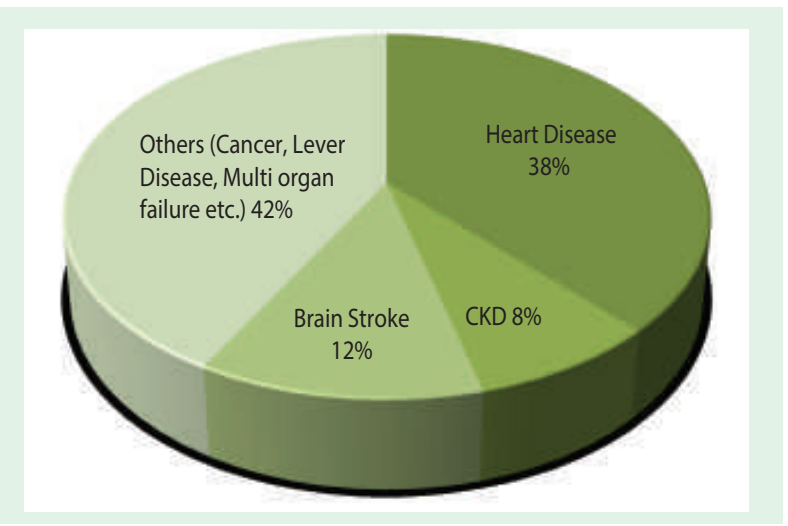

Fig. 2: Distribution of died patients by their causes of long-term mortality

\section{DISCUSSION:}

In the present study, the subjects who have had CABG surgery at ages 55 or $>55$ years had higher long-term mortality. Dramatic impact of age on survival was evident in age-cohorts of patients undergoing surgical and percutaneous revascularization. ${ }^{33}$ Studies also revealed older patients with higher all-cause mortality and other post-operative outcomes compared to younger patients. ${ }^{34,35}$ An understanding of the efficacy of CABG in patients of different ages is, therefore, needed to help inform clinical decision making. ${ }^{36}$

Women have a worse long-term outcome after CABG than men which is consistent with the previous studies. ${ }^{37}$ One reason may be that women in the present study were older than men (on an average $>1$ year older) at time of surgery. Women more often require urgent surgery and have a smaller body surface area and luminal diameter of the coronary artery than men, which may lead to more challenging surgery, and could possibly explain our findings. 38,39

However, impact of age associated mortality correlates on survival varies considerably. One would expect that the effect of age on mortality might be partially accounted for by other risk factors associated with the aging process, such as higher prevalence of diabetes mellitus, systemic hypertension and CKD. In the present study, diabetic patients carried significantly higher risk of long-term mortality than the non-diabetics. Similarly, previous studies showed diabetes mellitus to be independently associated with increased mortality among patients with ischemic cardiomyopathy and as an independent predictor of 5-year mortality and of lower 5-year cardiacrelated event-free survival. ${ }^{40,41}$ Smokers and CKD patients were also less likely to enjoylong-term survival as evident in the present study.

The prognosis of patients with ischemic heart disease has improved over the past 3 decades. ${ }^{42}$ This improvement in survival occurred despite a concomitant increase in comorbidity in CABG patients over the past 30 years. ${ }^{43}$ Possible explanations include improved surgical techniques, as well as wider use of post CABG medical treatments, such as statins and 
aspirin. ${ }^{44,45}$ Areas of future investigation include assessment of CABG-related morbidity, quality of life, and functional status.

\section{LIMITATIONS}

The 8-year time period that the patients in this study were recruited may introduce a time factor error. This is a common confounding factor of any large study over a prolonged period of time. LVEF was not found in discharge summary.

\section{CONCLUSION:}

Younger, male, non-smoker, non-diabetic patients may enjoy long-term survival following CABG surgery. Long-term survival outcome evaluation following CABG surgery have made cardiac surgeons motivated to refine their coronary revascularization techniques in order to maximize clinical effectiveness, limit costs and reduce invasiveness. Prediction of long-term survival can go a long way to determine the most appropriate post-discharge care strategies. This would essentially help patients and their doctors to implement behavioral \& therapeutic modifications to optimize benefit from surgery.

\section{REFERENCES:}

1. Strategic Plan for Surveillance and Prevention of Noncommunicable Diseases in Bangladesh 2011e2015. Dhaka: Directorate General of Health Services, Ministry of Health and Family Welfare; August 2011.

2. Department of Public Health and Primary Care, University of Cambridge. High-risk Hearts: A South Asian Epidemic. [Home page on the Internet] c2013 [cited 2013 Jul 3].

3. Favaloro RG. Saphenous vein autograft replacement of severe segmental coronary artery occlusions: operative technique. Ann Thorac Surg 1968;5:334-339.

4. The Veterans Administration Coronary Artery Bypass Surgery Cooperative Study Group. Eleven-year survival in the Veterans Administration randomized trial of coronary bypass surgery for stable angina. $N$ Engl J Med 1984;311:1333-1339.

5. Varnauskas E, European Coronary Surgery Study Group. Twelve-year follow-up of survival in the randomized European Coronary Surgery Study. N Engl J Med 1988;319:332-337.
6. Coronary Artery Surgery Study (CASS) principal investigators and associates. CASS: a randomized trial of coronary bypass surgery. Circulation 1983;68:939950.

7. Osswald BR, Blackstone EH, Tochtermann U, Thomas G, Vahl CF, Hagl S.The meaning of early mortality after CABG. Eur J Cardio thorac Surg 1999;15:401-7.

8. Billah B, Reid CM, Shardey GC, Smith JA. A preoperative risk predictionmodel for 30-day mortality following cardiac surgery in an Australiancohort. Eur $J$ Cardiothorac Surg 2010;37:1086-92.

9. Nashef SA, Roques F, Sharples LD, Nilsson J, Smith C, Goldstone AR et al. Euro SCORE II. Eur J Cardio thorac Surg 2012;41:12.

10. D’Errigo P, Seccareccia F, Rosato S, Manno V, Badoni G, Fusco $D$ et al.Comparison between an empirically derived model and the Euro SCOR Esystem in the evaluation of hospital performance: the example of the Italian CABG Outcome Project. Eur J Cardio thorac Surg 2008;33:325-33.

11. Carr BM, Romeiser J, Ruan J, Gupta S, Seifert FC, Zhu $W$ et al. Long-termpost-CABG survival: performance of clinical risk models versus actuarialpredictions. J Card Surg 2016;31:23-30.

12. Prospective randomised study of coronary artery bypass surgery in stable angina pectoris. Second interim report by the European Coronary Surgery Study Group. Lancet 1980;2:491-495.

13. Goldman S, Zadina K, Moritz T, Ovitt T, Sethi G, Copeland JG, Thottapurathu L, Krasnicka B, Ellis N, Anderson RJ, Henderson W. VA Cooperative Study Group. Long-term patency of saphenous vein and left internal mammary artery grafts after coronary artery bypass surgery: results from a Department of Veterans. Affairs Cooperative Study. Journal of American College of Cardiology 2004;44(11):2149-56.

14. Hosaina N, Aminb F, Rehmanc S, Koiralad B. Know thy neighbors: The status of cardiac surgery in the South Asian countries around India. Indian Heart Journal 2017:69.

15. Cardiovascular surgery in Bangladesh 2017. Bangladesh Journal of Cardiovascular Thoracic Anesthesiology 2018; 05(1):42.

16. Ibrahim Cardiac Hospital \& Research Institute annual performance report-2017:49.

17. Ahmed WA, Tully PJ, Baker RA, Knight JL. Survivals after isolated coronary artery bypass grafting in patients with severe left ventricular dysfunction. Ann Thorac Surg 2009;87:1106-12. 
18. Cardiovascular surgery in Bangladesh 2016. Bangl J Cardiovasc Thorac Anesthesiol 2017;04(1):51.

19. Coronary artery bypass surgery compared with percutaneous coronary interventions for multivessel disease: a collaborative analysis of individual patient data from ten randomised trials. Lancet 2009;373: 1190-7.

20. Loef BG, Epema AH, Navis G, Ebels T, Stegeman CA. Postoperative renal dysfunction and preoperative left ventricular dysfunction predispose patients to increased long-term mortality after coronary artery bypass graft surgery. Br J Anaesth 2009;102:749-55.

21. Serruys PW, Morice MC, Kappetein AP, Colombo A, Holmes DR, Mack MJ, et al. Percutaneous coronary intervention versus coronary-artery bypass grafting for severe coronary artery disease. N Engl J Med 2009; 360:961-72.

22. Thourani VH, Myung R, Kilgo P, Thompson K, Puskas JD, Lattouf $\mathrm{OM}$, et al. Long term outcomes after isolated aortic valve replacement in octogenarians: a modern perspective. Ann Thorac Surg 2008;86:1458-64.

23. Panagopoulou E, Montgomery A, Benos A. Quality of life after coronary artery bypass grafting: evaluating the influence of preoperative physical and psychosocial functioning. J Psychosom Res 2006;60:639-44.

24. Boudrez H, De Backer G, Comhaire B. Return to work after myocardial infarction: results of a longitudinal population based study. Eur Heart J 1994;15:32-36.

25. Caine N, Harrison SCW, Sharples LD, Wallwork J. Prospective study of quality of life before and after coronary artery bypass grafting. BMJ 1991;302: 511-516.

26. McGee HM, Graham T, Crowe B, Horgan JH. Return to work followmg coronary artery bypass surgery or percutaneous transluminal coronary angioplasty. Eur Heart J 1993;14:623-628.

27. Oberman A, Wayne JB, Kouchoukos NT, Charles ED, Russell RO, Rogers WJ. Employment status after coronary bypass surgery. Circulation 1982; 65(suppl II): 115-119.

28. Lahey SJ, Campos CT, Jennings B, Pawlow P, Stokes T, Levitsky S. Hospital readmission after cardiac surgery. Does "fast track" cardiac surgery result in cost saving or cost shifting? Circulation 1998;98(19 Suppl):35-40.

29. Zitser-Gurevich Y, Simchen E, Galai N, Braun D. Prediction of readmissions after CABG using detailed follow-up data: the Israeli CABG study (ISCAB). Med Care $1999 ; 37: 625-36$.
30. Stewart RD, Campos CT, Jennings B, Lollis SS, Levitsky S, Lahey SJ. Predictors of 30-day hospital readmission after coronary artery bypass. Ann Thorac Surg 2000; 70:169-74.

31. Herlitz J, Albertsson P, Brandrup-Wognsen G, et al. Predictors of hospital readmission two years after coronary artery bypass grafting. Heart 1997;77: 437-42.

32. Rahimtoola SH, Bennett AJ, Grunkemeier GL, Block P, Starr A. Survival at 15 to 18 years after coronary bypass surgery for angina in women. Circulation 1993;88(5 Pt 2):II71-8.

33. Taddei CF, Weintraub WS, Douglas JS, et al. Influence of age onoutcome after percutaneous transluminal coronary angioplasty. Am J Cardiol 1999;84:245-251.

34. Kieser TM, Lewin AM, Graham MM, et al. Out comes associated with bilateral internal thoracic artery grafting:The importance of age. Ann Thorac Surg 2011; 92:1269-76.

35. Benedetto $U$, Codispoti $M$. Age cutoff or the loss of survival benefit from use of radial artery in coronary artery bypasses grafting. J Thorac Cardiovasc Surg 2013; 146:1078-85.

36. Dalen M, Ivert T, Holzmann MJ, Sartipy U. Coronary artery bypass grafting in patients 50 years or younger: a Swedish nationwide cohort study. Circulation 2015; 131:1748-54.

37. Risum O, Abdelnoor M, Nitter-Hauge S, Levorstad K, SvennevigJL.Coronary artery bypass surgery in women and in men; early and long-termresults. A study of the Norwegian population adjusted by age and sex. Eur $\mathrm{J}$ Cardiothorac Surg 1997;11:539-546.

38. Khan SS, Nessim S, Gray R, Czer LS, Chaux A, Matloff J. Increased mortalityof women in coronary artery bypass surgery: evidence for referralbias. Ann Intern Med 1990;112:561-567.

39. Christakis GT, Weisel RD, Buth KJ, Fremes SE, Rao V, Panagiotopoulos KP, Ivanov J, Goldman BS, David TE. Is body size the cause for pooroutcomes of coronary artery bypass operations in women? J Thorac Cardiovasc Surg 1995;110:1344-1356; discussion 1356.

40. Domanski $M$, Krause-Steinrauf $H$, Deedwania $P$, et al. The effect of diabetes on outcomes of patients with advanced heart failure in the BEST trial. J Am Coll Cardiol 2003;42:914-22.

41. Rajakaruna C, Rogers CA, Suranimala C, Angelini GD, Ascione R. The effect of diabetes mellitus on patientsundergoingcoronary surgery: a risk adjusted analysis. J Thorac Cardiovasc Surg 2006;132:802-10. 
42. Royston $P$, Altman DG. External validation of a Cox prognostic model: principles and methods. BMC Med Res Methodol 2013;13:33.

43. Gardner SC, Grunwald GK, Rumsfeld JS, Mackenzie T, Gao D, PerlinjBet al. Risk factors for intermediate-term survival after coronary artery bypass grafting. Ann Thoracic Surgery 2001;72:2033-7.
44. Herlitz J, Haglid M, Albertsson P, Westberg S, Karlson B, Hartford $M$ et al. Short- and long-term prognosis after coronary artery bypass grafting in relation to smoking habits. Cardiology 1997;88:492-7.

45. Yap $\mathrm{CH}$, Mohajeri M, Ihle BU, Wilson AC, Goyal S, Yii M. Validation of Euro SCORE model in an Australian patient population. Aust ANZ J Surg 2005;75:5. 